\title{
STUDY OF THE EFFECTS OF HYPERTENSION ON PREGNANT MOTHERS AND THEIR NEW-BORN BABIES IN A MEDICAL COLLEGE IN KOLKATA
}

\author{
Sudipta Pramanick ${ }^{1}$ Pulak Panda ${ }^{2}$
}

${ }_{1}^{1}$ Postgraduate Trainee, Department of Physiology, KPC Medical College and Hospital, Jadavpur, Kolkata. 2 Professor and HOD, Department of Physiology, KPC Medical College and Hospital, Jadavpur, Kolkata.

\begin{abstract}
BACKGROUND

Hypertension in pregnancy not only affects the mother adversely, but also the new-born babies. Hypertension is one of the most common medical disorders complicating pregnancy. The World Health Organisation (WHO) systematically reviews maternal mortality worldwide and in developed countries; 16 percent of maternal deaths were reported to be due to hypertensive disorders (Khan, 2006). This proportion is greater than three other leading causes that include haemorrhage- 13 percent, abortion- 8 percent and sepsis- 2 percent.

Aims and Objectives- In this study, we intend to determine the adverse maternal and neonatal outcomes of hypertensive mothers and their new-born babies.
\end{abstract}

\section{MATERIALS AND METHODS}

In this prospective observational case-control study done in a two-year study period (2014 - 2016) in a Tertiary Care Medical College in Kolkata, 50 hypertensive mothers were taken as cases and 50 healthy pregnant women as controls. General parameters as well as the pregnancy outcome of mothers and their new-born babies were recorded by interview from bed-head case records and relevant blood tests and other tests done. All pregnant women diagnosed as pregnancy induced hypertension and other healthy pregnant women were periodically followed during their pregnancy and up to delivery required clinical observations, laboratory investigations done were recorded, complications of interest were noted of them along with that of their new-born infants.

\section{RESULTS}

Mean age, mean weight and mean BMI of hypertensive mothers at booking visit were significantly higher; $64 \%$ of hypertensive mothers had BMI $>25 \mathrm{~kg} / \mathrm{mt}^{2}$ as opposed to only $12 \%$ of that of control mothers; $40 \%$ had positive family history of hypertension in first degree relatives, $2 \%$ had a past history of PIH. The mean gestational age of neonates at delivery of both the groups was similar. Amongst statistically significant adverse maternal outcomes were higher performance of LUCS, occurrence of PPH associated preeclampsia/eclampsia, occurrence of oligohydramnios and associated GDM. Amongst statistically significa nt adverse neonatal outcomes were mean birth weight, occurrence of low birth weight new-borns (LBW), occurrence of Intrauterine Growth Restriction (IUGR), NICU admission > 24 hrs., mean Apgar score at 1 minute, mean Apgar score at 5 minutes, perinatal mortality and Respiratory Distress Syndrome (RDS). Birth trauma and congenital anomalies found were insignificant.

\section{CONCLUSION}

Hypertensive disorders of pregnancy are associated with significant adverse maternal and neonatal outcomes, which could be minimised with Institutional delivery and proper antenatal care.

\section{KEYWORDS}

Pregnancy Induced Hypertension, Intrauterine Growth Restriction, Perinatal Mortality, Respiratory Distress Syndrome.

HOW TO CITE THIS ARTICLE: Pramanick S, Panda P. Study of the effects of hypertension on pregnant mothers and their new-born babies in a medical college in Kolkata. J. Evolution Med. Dent. Sci. 2017;6(31):2497-2501, DOI: 10.14260/Jemds/2017/541

\section{BACKGROUND \\ Pregnancy Induced Hypertension (PIH) is one of the most common causes of both maternal and neonatal morbidity.[1] Pre-eclampsia is a multi-system disorder of the mother that affects the foetus, because of uteroplacental insufficiency.[2] In consequence, these children are at risk for intrauterine growth restriction and may be delivered prematurely. They may also suffer from the consequences of high rate of}

Financial or Other, Competing Interest: None.

Submission 09-03-2017, Peer Review 03-04-2017,

Acceptance 08-04-2017, Published 17-04-2017.

Corresponding Author:

Sudipta Pramanick,

\#8/1, Phanindrala Some Street,

P. O. Bhadrakali, District Hooghly-712232.

E-mail: drspwhite@yahoo.co.in

DOI: $10.14260 /$ jemds $/ 2017 / 541$ operative deliveries and the adverse effects of maternal drugs. American College of Obstetricians and Gynaecologists (2013) describes four types of hypertensive diseases.[1] 1. Gestational hypertension- BP $\geq 140 / 90 \mathrm{mmHg}$ for the first time in pregnancy after 20 weeks without proteinuria, evidence for the preeclampsia syndrome does not develop and hypertension resolves by 12 weeks postpartum; 2 . Preeclampsia and eclampsia syndrome; 3. Chronic Hypertension of any aetiology (known hypertension before pregnancy or hypertension diagnosed first time before 20 weeks of pregnancy); 4. Preeclampsia superimposed on chronic hypertension.

In this study, we intend to determine maternal and neonatal outcomes of hypertensive mothers and compare the same with that of healthy pregnant women and their newborn infants. 


\section{MATERIALS AND METHODS}

This prospective observational comparative case control study was conducted in the admitted pregnant female patients and their new-born infants in the Dept. of Obstetrics and Gynaecology, and the Dept. of Paediatrics, respectively in KPC Medical College and Hospital, Jadavpur, Kolkata, West Bengal. Ethical clearance was obtained from respective authority. Informed written consent was taken from all the subjects. Pregnant women, matched for ethnicity and race having hypertension, either chronic or pregnancy induced and their new-born infants were included in the study. This prospective observational case controlled study was carried for a period of 2 (two) years from inception (2014 - 2016); 50 cases of hypertensive pregnant women (i.e. both pregnancy induced hypertension and chronic hypertension) along with 50 controls of non-diabetic, non-hypertensive Healthy Pregnant Women (HPW) and their respective new-born infants were included in this study. The number of subjects for this study was $200.4 \sim 200$ with power $85 \%$. (From the different studies done, expected proportion of the patients, amongst the cases had been assumed to be 60\%). The formula used for sample size calculation is as follows:- $n=$ $4 \mathrm{pq} / \mathrm{L} 2$; where $\mathrm{n}=$ required sample size; $\mathrm{p}=0.20 ; \mathrm{q}=1-\mathrm{p} ; \mathrm{L}=$ Loss \% (Loss of Information). Inclusion criteria was all hypertensive pregnant women, i.e. both pregnant induced hypertension and chronic hypertension. All multiple pregnancies, pregnancies with serious comorbid conditions (anaemia, asthma, epilepsy, thyroid dysfunction, heart disease, etc. that can affect pregnancy outcome adversely; all pregnancies having complications of medical and/or surgical illness, malposition/malpresentation or those using drugs that can lead to hypertension as a side effect were excluded from the study (Exclusion criteria).

General parameters as well as the pregnancy outcome of mothers and their new-born babies was recorded by interview from bed-head case records and relevant blood tests and other tests done.

PIH defined as a systolic blood pressure level of $\geq 140$ $\mathrm{mmHg}$ and/or diastolic blood pressure level of $\geq 90 \mathrm{mmHg}$ on two separate occasions without proteinuria after 20 weeks of gestation in a previously normotensive woman. PIH screened in antenatal clinic in pregnant women $>20$ weeks of gestation. All pregnant women thus diagnosed and other healthy pregnant women were periodically followed during their pregnancy and up to delivery. All the required clinical observations, laboratory investigations done were recorded; complications of interest were noted of them along with that of their new-born infants. The data was arranged in a master chart in New Microsoft Office Excel Worksheet, version 2010 and analysed by SPSS (version-20). Continuous variables were analysed using Student's ' $t$ ' test and categorical variables by means of $\mathrm{x} 2$ analysis or Fisher exact test when appropriate. $\mathrm{P}$ values less than 0.05 were considered significant.

\section{RESULTS}

\begin{tabular}{|c|c|c|c|}
\hline Parameters & $\begin{array}{l}\text { Hypertensive Mothers } \\
\text { (n= 50) }\end{array}$ & $\begin{array}{c}\text { Control Mothers } \\
(n=50)\end{array}$ & P-value \\
\hline Religion (Hindu/Muslim/Others) & & & 0.097 \\
\hline - $\quad$ Hindu & $38(76)$ & $32(64)$ & \\
\hline - $\quad$ Muslim & $12(24)$ & $18(36)$ & \\
\hline - $\quad$ Others & $0(0)$ & $0(0)$ & \\
\hline Mean age on first visit (yrs.) & $26.5 \pm 23.4$ & $23.26 \pm 6.56$ & $0.000031^{*}$ \\
\hline Mean body weight (kgs) & $65.02 \pm 57.86$ & $55.12 \pm 26.23$ & $0.00001^{*}$ \\
\hline Mean BMI $\left(\mathrm{kg} / \mathrm{mt}^{2}\right)$ & $26.74 \pm 11.38$ & $22.69 \pm 3.88$ & $0.00001^{*}$ \\
\hline $\mathrm{BMI}>25 \mathrm{~kg} / \mathrm{mt}^{2}$ & $32(64)$ & $6(12)$ & $0.00001^{*}$ \\
\hline Parity (nullipara/multipara) & & & 0.346 \\
\hline - $\quad$ Nullipara & $24(48)$ & $26(52)$ & \\
\hline - $\quad$ Multipara & $26(52)$ & $24(48)$ & \\
\hline Family history of hypertension in first degree relatives & $20(40)$ & $0(0)$ & $0.0036^{*}$ \\
\hline Past history of PIH in previous pregnancy & $1(2)$ & $0(0)$ & $0.16^{*}$ \\
\hline Education level $\left(<10^{\text {th }}\right.$ or $>10^{\text {th }}$ Std. $)$ & & & 0.112 \\
\hline - $\quad<10$ th Std. & $13(26)$ & $8(16)$ & \\
\hline - $\quad$ 10th or $>10$ th Std. & $37(74)$ & $42(84)$ & \\
\hline Smoking history & $1(2)$ & $0(0)$ & 0.16 \\
\hline Mean gestational age of neonates at delivery (weeks) & $37.11 \pm 4.33$ & $36.54 \pm 4.15$ & 0.086 \\
\hline
\end{tabular}

*Statistically significant at P-value $<0.05$; BMI- Body Mass Index; Data are given as number (percentage) and mean \pm standard deviation.

In our study $76 \%$ of all hypertensive mothers are Hindus, while only $64 \%$ are Hindus in the control group which is statistically insignificant ( $p=0.097)$. Mean age, mean weight and mean BMI of hypertensive mothers at booking visit are higher $(26.5 \pm 23.4),(65.02 \pm 57.86)$ and $(26.74 \pm 11.38)$ respectively than that of control mothers $(23.26 \pm 2.56)$ (55.12 \pm 5.12$)$ and $(22.69 \pm 1.97)$ respectively, which are all statistically significant; $64 \%$ of hypertensive mothers have 
BMI $>25 \mathrm{Kg} / \mathrm{mt}^{2}$ as opposed to only $12 \%$ of that of control mothers, which is statistically significant; $40 \%$ have positive family history of hypertension in first degree relatives (vs $0 \%$ in the control group), $2 \%$ have a past history of PIH (vs $0 \%$ in the control group), all of which are statistically significant; $52 \%$ of hypertensive mothers (vs $48 \%$ in control group) are multipara and $74 \%$ have an educational level of that of 10 th standard or above (vs $84 \%$ in the control group). These two are statistically insignificant. The mean gestational age of neonates at delivery of both the groups are similar (37.11 \pm 4.33) vs (36.54 \pm 4.15$)$ and statistically not significant. (Table-1) Amongst statistically significant adverse maternal outcomes were performance of LUCS $(82 \%$ in the cases vs only $16 \%$ in the controls), occurrence of PPH ( $6 \%$ in the cases vs $0 \%$ in the controls), associated preeclampsia/eclampsia ( $36 \%$ in the hypertensive group $\mathrm{v} / \mathrm{s} 0 \%$ in the control group), occurrence of oligohydramnios $(22 \%$ in the cases $\mathrm{v} / \mathrm{s} 0 \%$ in the controls) and associated GDM (14\% in the cases v/s $0 \%$ in the controls).

\begin{tabular}{|c|c|c|c|}
\hline Parameters & $\begin{array}{c}\text { Hypertensive } \\
\text { Group } \\
\text { (n= 50) }\end{array}$ & $\begin{array}{c}\text { Control } \\
\text { Group } \\
(n=50)\end{array}$ & P-value \\
\hline Induction of Labour & $1(2)$ & $4(8)$ & 0.086 \\
\hline LUCS & $41(82)$ & $8(16)$ & 0.00001* \\
\hline $\mathrm{PPH}$ & $3(6)$ & $0(0)$ & $0.04^{*}$ \\
\hline $\begin{array}{l}\text { Associated } \\
\text { Preeclampsia/ } \\
\text { Eclampsia }\end{array}$ & $18(36)$ & $0(0)$ & $0.00001^{*}$ \\
\hline Preterm Labour & $26(52)$ & $21(42)$ & 0.16 \\
\hline PROM & $6(12)$ & $4(8)$ & 0.255 \\
\hline Oligohydramnios & $11(22)$ & $0(0)$ & 0.000167* \\
\hline Associated GDM & $7(14)$ & $0(0)$ & 0.00287* \\
\hline Maternal Death & $2(4)$ & $0(0)$ & 0.078 \\
\hline
\end{tabular}

*Statistically significant at P-value < 0.05; BMI- Body Mass Index; LUCS- Lower Uterine Caesarean Section; PPH- PostPartum Haemorrhage; PROM- Premature Rupture of Membrane; GDM- Gestational Diabetes Mellitus; Data are given as number (percentage).

Amongst other adverse maternal outcomes were induction of labour, associated preterm labour, Premature
Rupture of Membrane (PROM) and occurrence of maternal death, all of which were statistically insignificant. (Table-2) Amongst statistically significant adverse neonatal outcomes were mean birth weight $(2.38 \pm 0.42 \mathrm{Kgs}$ in the cases v/s 2.56 $\pm 0.04 \mathrm{Kgs}$ in the controls), occurrence of low birth weight new-borns (LBW) (60\% in the cases $\mathrm{v} / \mathrm{s} 24 \%$ in controls), occurrence of Intrauterine Growth Restriction (IUGR) (54\% in the cases $\mathrm{v} / \mathrm{s} 2 \%$ in the controls), NICU admission $>24 \mathrm{hrs}$ (62\% in the cases v/s $8 \%$ in the controls), mean Apgar score at 1 minute $(5.78 \pm 5.4$ in the cases $\mathrm{v} / \mathrm{s} 8.16 \pm 0.79$ in the controls), mean Apgar score at 5 minutes (7.8 \pm 8.61 in the cases v/s $9.42 \pm 0.25$ in the controls), perinatal mortality $(18 \%$ in the cases $\mathrm{v} / \mathrm{s} 0 \%$ in the control group) and Respiratory Distress Syndrome (RDS) (32\% in the cases v/s $0 \%$ in the control group). Amongst other adverse neonatal outcomes were occurrence of birth trauma and congenital anomalies, which were statistically insignificant (Table-3).

\begin{tabular}{|c|c|c|c|}
\hline Parameters & \begin{tabular}{|c|} 
Hypertensive \\
Group \\
$(\mathrm{n}=\mathbf{5 0})$
\end{tabular} & $\begin{array}{l}\text { Control } \\
\text { Group } \\
(n=50)\end{array}$ & P-value \\
\hline $\begin{array}{l}\text { Mean Birth Weight } \\
\text { (Kgs) }\end{array}$ & $2.38 \pm 0.42$ & $2.56 \pm 0.04$ & $0.0286^{*}$ \\
\hline LBW $(<2500$ gm $)$ & 301 & $12(24)$ & $0.00001^{*}$ \\
\hline IUGR & $27(54)$ & $1(2)$ & $0.00001^{*}$ \\
\hline $\begin{array}{c}\text { NICU admission }>24 \\
\text { hrs. }\end{array}$ & $31(62)$ & $4(8)$ & $0.00001^{*}$ \\
\hline Mean Apgar 1 & $5.78 \pm 5.4$ & $8.16 \pm 0.79$ & $0.00001^{*}$ \\
\hline Mean Apgar 5 & $7.8 \pm 8.61$ & $9.42 \pm 0.25$ & $0.0001^{*}$ \\
\hline Apgar $5(<7)$ & 2) & $0(0)$ & $0.00001^{*}$ \\
\hline Perinatal mortality & $9(18)$ & $0(0)$ & $0.00072^{*}$ \\
\hline RDS & $16(32)$ & $3(6)$ & $0.00038^{*}$ \\
\hline Birth Trauma & $2(4)$ & $0(0)$ & 0.078 \\
\hline Congenital anomaly & $2(4)$ & $0(0)$ & 0.078 \\
\hline \multicolumn{4}{|c|}{$\begin{array}{l}\text { Table 3. Comparison of Neonatal Outcomes } \\
\text { between Hypertensive and Control Groups }\end{array}$} \\
\hline
\end{tabular}

*Statistically significant at P-value < 0.05; LBW- low birth weight; IUGR- Intrauterine Growth Restriction; NICUNeonatal Intensive Care Unit; RDS- Respiratory Distress Syndrome; Data are given as number (percentage) and mean \pm standard deviation.

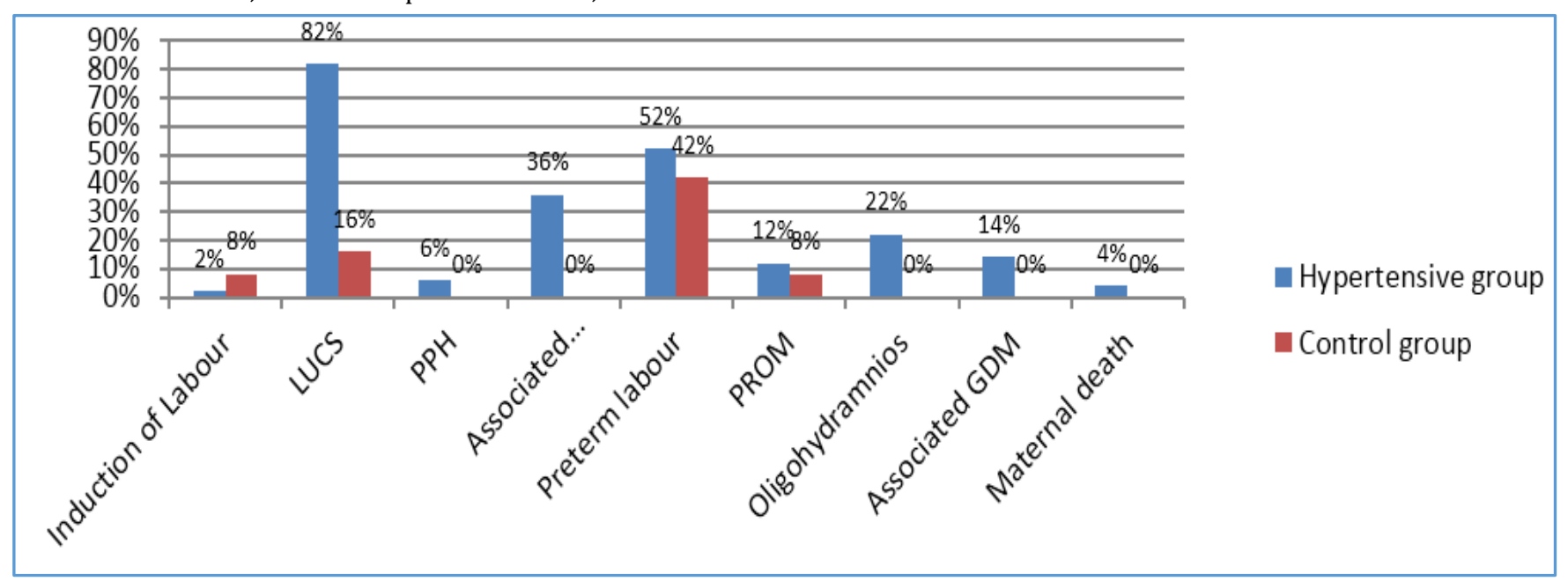

Diagram 1. Comparison of Maternal Outcomes between Hypertensive and Control Groups 


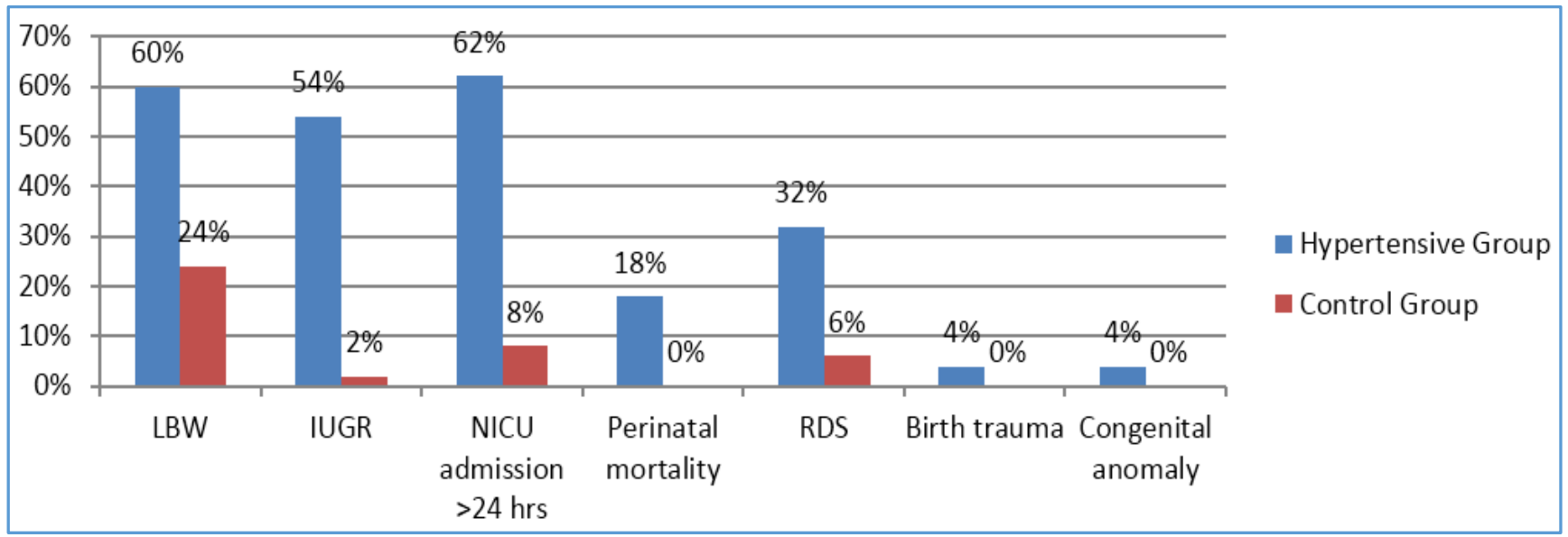

Diagram 2. Comparison of Neonatal Outcomes between Hypertensive and Control Groups

\section{DISCUSSION}

Hypertensive Disorders of Pregnancy (HDP) is a global problem and complicates approximately $10-17 \%$ of all pregnancies. ${ }^{[3]}$ The incidence of PIH in India ranges from 5 $15 \%{ }^{[4]}$ Obesity is a risk factor for preeclampsia. Even in women of normal weight, there is a linear relationship between pre-pregnancy body mass index and the frequency of preeclampsia.[5]

In the present study, low birth weight and IUGR babies were statistically significant in the study group, viz. $60 \%$ and $54 \%$ respectively $(\mathrm{p}<0.05)$. This is in accordance with the result of Fatemeh et al (2010),[6] who studied 100 hypertensive and 100 normotensive mothers and revealed a difference in the birth weight.

Neonatal intensive care unit admission and duration of stay was higher in the study group (62\% in study group vs. $8 \%$ in the control group). This observation is similar to that of Fatemah et al (2010).[6] The reason for the prolonged stay in NICU was prematurity and its associated complications. Sheffer-Mimoum et al (2002) ${ }^{[7]}$ also observed that SGA, LBW and preterm delivery was significantly higher in woman with HDP. The perinatal mortality was higher in the study group than control in the present study (18\% in the study group $\mathrm{v} / \mathrm{s}$ $0 \%$ in the control group). Vandenbosche and Kirchner (1998) ${ }^{[8]}$ also stated that the infants of hypertensive mothers have three-fold increase in perinatal mortality as compared to infants with IUGR who are born to normotensive mothers. The incidence of Post-Partum Haemorrhage is found to be $6 \%$ in our study. The incidence rate correlates with $10.20 \%$ for Leduc et al (1992).[9] The incidence of maternal mortality in our study was $4 \%$, which well co-relates with that conducted by Hagragi $(2006)^{[10]}$ was found to be $2.3 \%$. The incidence of perinatal mortality in our study was $18 \%$, which is comparable to Gaddi et al (2001)[11] 22.3\%.

Our study records a mean GA of new-borns of $37.11 \pm$ 4.33 weeks (not significantly different from that of the control group). Maternal Body Mass Index (BMI) is a strong risk factor for HDP during pregnancy, leading to complications during pregnancy, delivery and post-partum for both mother and offspring. ${ }^{[12,13]}$ The mean BMI of the hypertensive mothers in our study was $26.74 \pm 11.38$, which was statistically significant. Evidence suggests a significant reduction in neonatal respiratory morbidity when gestation is extended beyond 34 weeks, a benefit seen for each week increase in gestational age up to term. ${ }^{[14,15]}$ In our study, the incidence of RDS was $32 \%$ (vs $6 \%$ in the control group) which is significant.

In present study, prevalence of hypertension in pregnancy was found significantly higher in women with history of hypertension in previous pregnancy $(2 \%)$. Similarly, Nisar et al[16] and Tebeu et al[17] found significant association between history of hypertension during previous pregnancy and hypertension in current pregnancy. Preeclampsia is a progressive disorder and the only definitive management is the delivery of the foetus ${ }^{[18]}$ to minimise the maternal morbidity and mortality. However, this increases the chance of premature delivery with low odds of child survival.[19] As noted, preterm babies are more likely to be admitted to the neonatal intensive care unit, have assisted ventilation, to be of low birth weight and small for gestational age and to develop respiratory distress syndrome than term infants.[20,14] $62 \%$ of the new-borns in the study group were admitted in NICU, which by far is the most common neonatal complication in our study vs. only $8 \%$ in the control group. In the present study, rate of caesarean delivery and induction of labour were $82 \%$ and $2 \%$ respectively. Similar studies by Oladokun A et al,[21] Miguil M et al[22] and Dissanayake VH et al[23] revealed caesarean section rates as $60 \%, 71 \%$ and $78 \%$ respectively.

Masodkar et al (1985) [24] also observed a low Apgar score in toxaemia of pregnancy. The present study has got similar findings as well. Apgar score $<7$ at 5 minutes is $12 \%$ in the hypertensive group vs $0 \%$ in the control group, which is significant.

Young and nulliparous women are particularly vulnerable to developing preeclampsia, whereas older women are at greater risk for chronic hypertension with superimposed preeclampsia. The incidence is markedly influenced by race and ethnicity and thus by genetic predisposition. The incidence of preeclampsia in multiparas is also variable, but is less than that for nulliparas.[25]

Although smoking during pregnancy causes various adverse pregnancy outcomes; ironically, it has consistently been associated with a reduced risk for hypertension during pregnancy (Bainbridge, 2005; Zhang, 1999).[1] Women with preeclampsia in the first pregnancy are at greater risk in a second pregnancy compared with women normotensive during their first pregnancy (McDonald, 2009).[1] The hospital incidence of Eclampsia in India ranges from 1 in 500 to 1 in 30 . It is more common in primigravidae $(75 \%)$, five times 
more common in twins than in singleton pregnancies and occurs between the 36th week and term in more than $50 \%$.

\section{CONCLUSION}

Hypertensive disorders of pregnancy are a common complication in antenatal women and are a major cause of maternal and foetal morbidity and mortality. Age $>25$ years and obesity are significant risk factors. Our study concludes that there is a significant rise of caesarean sections and PPH in mothers having HDP and also there is an increased risk of delivering low birth weight, IUGR and preterm babies increasing their NICU admission rate. It also increases RDS and perinatal mortality rate. The study highlights the importance of Institutional deliveries of women combined with effective antenatal care. Hence, health education and awareness among the people and primary health workers regarding this health issue is necessary in bringing down the maternal and neonatal morbidity and mortality.

\section{Limitations}

Small sample size and lack of followup of the mothers and their babies were the limitation of this study. However, this study shows the direction of further long-term follow-up study to gauge the scourge of this disease in the society.

\section{REFERENCES}

[1] Cunningham FG, Leveno KJ, Bloom SL, et al. Hypertensive disorders. 24th edn. Williams obstetrics. United States of America: McGraw-Hill Companies 2014:728-79.

[2] Sibai BM. Diagnosis, prevention and management of eclampsia. Obstet Gynecol 2005;105(2):402-10.

[3] Gilstrap LC, Ramin SM. Diagnosis and management of preeclampsia and eclampsia. In: clinical management guidelines for obstetrician-gynaecologist. ACOG practice bulletin 2002;33(1):1-9.

[4] Raddi SA, Nayak BS, Prakash R, et al. Stress, coping strategies, quality of life and lived experiences of women with pregnancy-induced hypertension. South Asian Federation of Obstetrics \& Gynecology 2009;1(1):65-8.

[5] Bodnar LM, Ness RB, Markovic N, et al. The risk of preeclampsia rises with increasing prepregnancy body mass index. Ann Epidemiol 2005;15(7):475-82.

[6] Fatemeh T, Marziyeh G, Nayereh G, et al. Maternal and perinatal outcome in nulliparous women complicated with pregnancy hypertension. Journal of Pakistan Medical Association 2010;60(9):707-10.

[7] Sheffer-Mimoum G, Mashiach S, Dor J, et al. Factors influencing the obstetrics and perinatal outcome after oocyte donation. Human Reproduction 2002;17(10):2636-40.

[8] Vandenbosche RC, Kirchner JT. Intrauterine growth retardation. American Family Physicians 1998;58(6):1384-90.

[9] Leduc L, Wheeler JM, Krishon B, et al. Coagulation profile in sever preeclampsia. Obs Gyn 1992; 79(1):14-8.
[10] Kumari P, Singh S, Khatun S, et al. Comparative study of vaginal delivery and caesarean section in antepartum eclampsia at tertiary care hospital. Int J Reprod Contracept Obstet Gynecol 2017;6(2):457-60.

[11] Gaddi SS, Shantha S. A study of perinatal mortality in Headquarters hospital Bellary. J Obst and Gyn of India 2001;51(6):101-3.

[12] Duckitt K, Harrington D. Risk factors for pre-eclampsia at antenatal booking: systematic review of controlled studies. BMJ 2005;330:565.

[13] Black RE, Victora CG, Walker SP, et al. Maternal and child undernutrition and overweight in low-income and middle-income countries. Lancet 2013;382(9890):427-51.

[14] Jain L. Respiratory morbidity in late-preterm infants: prevention is better than cure. American Journal of Perinatology 2008;25(2):75-8.

[15] Roth-Kleiner M, Wagner BP, Bachmann D, et al. Respiratory distress syndrome in near-term babies after caesarean section. Swiss Medical Weekly 2003;133(19-20):283-8.

[16] Nisar N, Memon A, Sohoo NA, et al. Hypertensive disorders of pregnancy: frequency, maternal and fetal outcomes. Pak Armed Forces Med J 2010;60(1):113-8.

[17] Tebeu PM, Foumane P, Mbu R, et al. Risk factors for hypertensive disorders in pregnancy: a report from the maroua regional hospital, Cameroon. J Reprod Infertil 2011;12(3):227-34.

[18] ACOG Committee on Obstetric Practice. ACOG practice bulletin. Diagnosis and management of preeclampsia and eclampsia. Number 33, january 2002. American college of obstetricians and gynecologists. Int J Gynaecol Obstet 2002;77(1):67-75.

[19] Barton JR, Barton LA, Istwan NB, et al. Elective delivery at $340 / 7$ to $366 / 7$ weeks gestation and its impact on neonatal outcomes in women with stable mild gestational hypertension. Am J Obstet Gynecol 2011;204(1):44 e1-5.

[20] Dudell GG, Jain L. Hypoxic respiratory failure in the late preterm infant. Clin Perinatol 2006;33(4):803-30.

[21] Oladokun A, Okewole AI, Adewole IF, et al. Evaluation of cases of eclampsia in the university college hospital, Ibadan over a 10 year period. West Afr J Med 2000;19(3):192-4.

[22] Miguil M, Chekairi A. Eclampsia, study of 342 cases. Hypertens Pregnancy 2008;27(2):103-11.

[23] Dissanayake VH, Samarasinghe HD, Morgan L, et al. Morbidity and mortality associated with preeclampsia at two tertiary care hospitals in Sri Lanka. J Obstet Gynaecol Res 2007;33(1):56-62.

[24] Masodkar AR, Kalamkar LR, Patki PS. Histopathology of placenta and its correlation with foetal outcome. J Obstet Gynecol India 1985;35:294-300.

[25] DeBoer T, Wewerka S, Bauer PJ, et al. Explicit memory performance in infants of diabetic mothers at 1 year of age. Dev Med Child Neurol 2005;47(8):525-31. 